\title{
Doubling the Infliximab Dose Versus Halving the Infusion Intervals in Crohn's Disease Patients with Loss of Response
}

\author{
Lior Katz, MD, ${ }_{1}^{1}$ Javier P. Gisbert, MD, PhD, ${ }^{2}$ Beth Manoogian, MD, ${ }^{3}$ Kirk Lin, MD, ${ }^{4}$ Casper Steenholdt, $M D_{,}{ }^{5}$ \\ Gerassimos J. Mantzaris, MD, PhD, ${ }^{6}$ Ashish Atreja, MD, MPH, Yulia Ron, $M D_{1}{ }^{8}$ Arun Swaminath, $M D_{1}{ }^{9}$ \\ Somal Shah, MD, ${ }^{10}$ Ailsa Hart, PhD, MRCP, ${ }^{11}$ Peter Laszlo Lakatos, MD, PhD, ${ }^{12}$ Pierre Ellul, MD, ${ }^{13}$ \\ Eran Israeli, MD, ${ }^{14}$ Mads Naundrup Svendsen, $M D^{15}$ C. Janneke van der Woude, MD, PhD, ${ }^{16}$ \\ Konstantinos H. Katsanos, MD, PhD,,$^{17}$ Laura Yun, MD, ${ }^{18}$ Epameinondas V. Tsianos, MD, PhD, ${ }^{17}$ \\ Torben Nathan, $M D^{15}$ Maria Abreu, $M D_{,}^{10}$ Iris Dotan, $M D_{,}^{8}$ Bret Lashner, MD, MPH, Jorn Brynskov, $M D^{7}{ }^{5}$ \\ Jonathan P. Terdiman, MD, ${ }^{4}$ Peter D.R Higgins, MD, PhD, ${ }^{3}$ Maria Chaparro, MD, PhD, ${ }^{2}$ \\ and Shomron Ben-Horin, MD
}

Background: Intensifying infliximab therapy is often practiced in Crohn's disease (CD) patients losing response to the drug but there are no data if halving the interval is superior to doubling the dose. We aimed to assess the efficacy of infliximab dose intensification by interval-halving compared with dose-doubling.

Methods: A multicenter retrospective study of $\mathrm{CD}$ patients losing response to infliximab was undertaken. The clinical outcome of patients whose infusion intervals were halved ( $5 \mathrm{mg} / \mathrm{kg} / 4$ weeks) was compared with patients treated by dose-doubling (10 mg/kg/8 weeks).

Results: In all, 168 patients were included from 18 centers in Europe, USA, and Israel. Of these, 112 were intensified by dose-doubling and 56 received interval-halving strategy. Early response to dose-escalation was experienced by 86/112 (77\%) patients in the dose-doubling group compared with $37 / 56$ patients $(66 \%)$ in the interval-halving group (odds ratio [OR] 1.7, 95\% confidence interval $[\mathrm{CI}] 0.8-3.4, P=0.14$ ). Sustained clinical response at 12 months postescalation was maintained in $50 \%$ of patients in the dose-doubling group compared with $39 \%$ in the intervalhalving group (OR 1.5, 95\% CI $0.8-2.9, P=0.2)$. On multivariate analysis, predictors of long-term response to escalation were a nonsmoking status, CD diagnosis between 16-40 years of age, and normal C-reactive protein (CRP).

Conclusions: Dose intensification leads to a sustained regained response in $47 \%$ of CD patients who lost response to standard infliximab dose, but halving the infusion intervals is probably not superior to dose-doubling. Given the costs and patient inconvenience incurred by an additional infusion visit, the dose-doubling strategy may be preferable to the interval-halving strategy.

(Inflamm Bowel Dis 2012;18:2026-2033)

Key Words: inflammatory bowel disease, Crohn's disease, infliximab

T he anti-tumor necrosis factor alpha (TNF- $\alpha$ ) infliximab is a monoclonal mouse-human chimeric IgG1 construct that was proven efficacious in both Crohn's disease (CD) and in ulcerative colitis. ${ }^{1-3}$ Although episodic administration of the drug was initially common, it was later shown that scheduled therapy results in a higher rate of

Received for publication December 20, 2011; Accepted January 9, 2012.

From the ${ }^{1}$ Gastroenterology Department, Sheba Medical Center, Tel Hashomer, Tel-Aviv University, Israel, ${ }^{2}$ Hospital Universitario de La Princesa, Instituto de Investigación Sanitaria Princesa (IP) and Centro de Investigación Biomédica en Red de Enfermedades Hepáticas y Digestivas (CIBEREHD), Madrid, Spain, ${ }^{3}$ University of Michigan Medical Center, Ann Arbor, USA, ${ }^{4}$ Division of Gastroenterology, Department of Medicine, University of California San Francisco, San Francisco, USA, ${ }^{5}$ Department of Medical Gastroenterology, Herlev Hospital, University of Copenhagen, Denmark, ${ }^{6} 1$ st Department of Gastroenterology, Evangelismos Hospital, Athens, Greece, ${ }^{7}$ Center for Inflammatory Bowel Disease at Cleveland Clinic, Digestive Diseases Institute in Cleveland, Ohio, USA, ${ }^{8}$ Division of Gastroenterology, Tel-Aviv Medical Center, Israel, ${ }^{9}$ Division of Gastroenterology, Columbia university Presbyterian hospital, New-York, New-York, USA, ${ }^{10}$ University of Miami Miller School of Medicine, Miami, Florida, USA, ${ }^{11}$ St. Marks Hospital, London, United Kingdom, ${ }^{12} 1$ st Department of Medicine, Semmelweis University, Budapest, Hungary,

${ }^{13}$ Gastroenterology Department, Mater Dei Hospital, Msida, Malta, ${ }^{14}$ Gastroenterology Department, Hadassah Medical Center, Jerusalem, Israel, ${ }^{15}$ Medicinsk afdeling Vejle, Sygehus Hospital, Denmark, ${ }^{16}$ Erasmus Medical Center, Rotterdam The Netherlands, ${ }^{17}$ Hepato-Gastroenterology Unit, 1st Department of Internal Medicine, Medical School of Ioannina, Ionnina, Greece, ${ }^{18}$ Northwestern University Feinberg School of Medicine, Chicago, Illinois, USA. *Spanish data were provided by the Spanish collaborative group ENICMAD.

Supported in part by the 'Talpiot' Medical Leadership program of Sheba Medical Center (to S.B.H.).

Reprints: Shomron Ben-Horin, MD, Gastroenterology Department, Sheba Medical Center, Tel Hashomer 52621, Israel (e-mail: sben-horin@013.net.il).

Copyright $\odot 2012$ Crohn's \& Colitis Foundation of America, Inc.

DOI 10.1002/ibd.22902

Published online 31 January 2012 in Wiley Online Library (wileyonlinelibrary.com). 
maintained remission and a reduced number of hospitalizations. ${ }^{4,5}$ However, despite its efficacy in inducing and maintaining remission, up to $46 \%$ of the patients may experience loss of response (LOR) and require dose escalation of infliximab within 12 months of commencing therapy. ${ }^{6,7}$ Differing intensification strategies, either by shortening the interval between infusions or by increasing the dose, are often attempted strategies to regain response in these patients. Nonetheless, the optimal protocol for infliximab dose escalation remains to be determined. Pharmacodynamic mathematic modeling has lead investigators in the ATTRACT study of rheumatoid arthritis to propose that shortening the infusion intervals would attain higher area-under-curve (AUC) concentrations of infliximab compared with increasing the dose. ${ }^{8}$ However, there are no published studies directly comparing the two policies, i.e., doubling the dose to $10 \mathrm{mg} / \mathrm{kg} / 8$ week versus halving the infusion intervals to $5 \mathrm{mg} / \mathrm{kg} / 4$ weeks. Although they provide an equal cumulative amount of medication, a comparison between these two strategies is desirable given that the direct costs incurred and patient inconvenience are probably greater with the interval-halving approach.

Therefore, the aim of the present study was to investigate the efficacy of halving the infusion intervals to once in 4 weeks $(5 \mathrm{mg} / \mathrm{kg} / 4 \mathrm{w})$ as compared with a double-dose approach $(10 \mathrm{mg} / \mathrm{kg} / 8 \mathrm{w})$ in $\mathrm{CD}$ patients losing response to infliximab.

\section{MATERIALS AND METHODS}

\section{Study Design and Population}

This was an observational retrospective study of infliximab-treated CD patients in the years 2000-2010 at the Gastroenterology Departments of the participating tertiary medical centers. The study population included patients who had lost response to maintenance infliximab infusions of $5 \mathrm{mg} / \mathrm{kg}$ every 8 weeks as per their treating physician's judgment and who were directly dose-intensified by either $5 \mathrm{mg} / \mathrm{kg} / 4$ weeks or by $10 \mathrm{mg} / \mathrm{kg} / 8$ weeks. Patients who were first dose-escalated to other regimens such as $5 \mathrm{mg} / \mathrm{kg} / 6$ weeks or $7.5 \mathrm{mg} / \mathrm{kg} / 8$ weeks were excluded, as were patients who were dose-escalated during the induction phase (i.e., before the fourth infliximab infusion). Patients were identified in the participating centers by a search of a computerized inflammatory bowel disease (IBD) database (where available) or by a manual screen of all charts of patients receiving infliximab at the designated time period. The patients were divided into two groups according to the intensification regimen originally prescribed by their physician: a $5 \mathrm{mg} / \mathrm{kg}$ every 4 weeks group versus a $10 \mathrm{mg} / \mathrm{kg}$ every 8 weeks group. Patient charts were reviewed by an investigator in the participating institution and clinical and laboratory parameters were recorded. The clinical outcome of regained response at the first clinic visit after the first intensified dose infusion (immediate response) and after 1 year (sustained response) was compared for the patients in the two groups. The study was approved by the Institutional Ethics Committee of the Sheba Medical Center and also approved or exempted by the local Ethics Committees of the participating centers.

\section{Definitions}

Maintenance dosing was defined as at least one 8-weekinterval infusion of infliximab following the induction course and prior to any dose escalation. Immediate response to intensification was defined as improvement of the symptoms at the first clinic visit (within 4-8 weeks) after dose-intensification of infliximab as per the treating physician judgment, coupled with a decision to continue the intensified dose strategy without alterations. Long-term sustained response was defined as improvement of the symptoms on intensified therapy lasting at least 1 year without any further alterations of the therapeutic regimen. Failure of the intensified therapeutic strategy was defined by the absence of improvement of the symptoms of disease and by a decision by the treating physician to increase the dose or shorten the dose interval of infliximab further, add immunomodulator or corticosteroids therapy, switch to another anti-TNF medication (adalimumab/certolizumab) or biologic, or refer for CD-related surgery. In attempt to distinguish between possibly different mechanisms of LOR, we also separately subanalyzed patients with early LOR (defined as symptoms rapidly reemerging less than 4 weeks after the last infusion) versus those with late LOR (symptoms reemerging 1-3 weeks before the next maintenance infusion).

\section{Statistical Analysis}

Continuous variables were analyzed by a two-tailed Student's $t$-test or the Mann-Whitney $U$-test, as appropriate, and categorical variables were analyzed by Fisher's exact test. Odds ratio (OR) and 95\% confidence intervals (CI) were computed for all variables compared. For continuous variables, the ORs were computed after division of the cohort to above/ below the median value for the respective parameter. Multivariate analysis was preformed by entering all parameters varying between groups on univariate analysis with a statistical significance of $P<0.1$ into a backwards logistic regression model. Regarding sample size, based on the data from our preliminary study and the ATTRACT study investigators' postulation of superiority of interval-shortening, 8,9 we assumed a $20 \%$ rate of maintained response to double-dose at 12 months versus a $45 \%$ rate for 12 -month response by intervalhalving. To detect this difference with a power of $80 \%$ and with a level of $5 \%$ we computed that 52 patients in each arm (total of 104) would be required. All statistics were performed using MedCalc software (Mariakerke, Belgium). A two-tailed $P<0.05$ was considered statistically significant. 


\begin{tabular}{|c|c|c|c|c|c|}
\hline & & $\begin{array}{l}\text { Entire cohort } \\
\quad(n=168)\end{array}$ & $\begin{array}{c}10 \mathrm{mg} / \mathrm{kg} / 8 \mathrm{w} \\
(n=112)\end{array}$ & $5 \underset{(n=56)}{5 \mathrm{mg} / \mathrm{kg} / 4 \mathrm{w}}$ & $P$-value \\
\hline \multicolumn{2}{|l|}{ Female gender } & $85(51 \%) 18.1$ & $57(51 \%)$ & $28(50 \%)$ & 0.9 \\
\hline \multicolumn{2}{|l|}{ Mean age (median) } & $25 \pm 13(24)$ & $25 \pm 12(24)$ & $26 \pm 14(23)$ & 0.6 \\
\hline \multicolumn{2}{|l|}{ Smoking* } & $32(20 \%)$ & $16(17 \%)$ & $16(33 \%)$ & 0.03 \\
\hline \multicolumn{2}{|c|}{ Mean duration of disease in years (median) } & $12 \pm 8(10)$ & $13 \pm 9(11)$ & $10 \pm 9(7)$ & 0.04 \\
\hline \multicolumn{2}{|c|}{ Extraintestinal manifestations* } & $49(40 \%)$ & $34(43 \%)$ & $15(30 \%)$ & 0.2 \\
\hline \multicolumn{2}{|l|}{ Prior anti-TNF (adalimumab) failure } & $4(2 \%)$ & $3(3 \%)$ & $1(2 \%)$ & 0.7 \\
\hline \multicolumn{2}{|l|}{ History of episodic infliximab therapy* } & $22(15 \%)$ & $15(15 \%)$ & $7(13 \%)$ & 0.7 \\
\hline \multicolumn{2}{|l|}{ Previous intestinal surgery* } & $56(39 \%)$ & $41(43 \%)$ & $15(32 \%)$ & 0.3 \\
\hline \multirow[t]{3}{*}{ Age at diagnosis* } & $<16$ & $27(17 \%)$ & $20(20 \%)$ & $7(13 \%)$ & 0.3 \\
\hline & $16-40$ & $107(67 \%)$ & $68(67 \%)$ & $39(74 \%)$ & 0.4 \\
\hline & $>40$ & $26(16 \%)$ & $13(13 \%)$ & $7(13 \%)$ & 0.9 \\
\hline \multirow[t]{4}{*}{ Location } & Upper & $7(4 \%)$ & $6(5 \%)$ & $1(2 \%)$ & 0.4 \\
\hline & Small bowel & $24(14 \%)$ & $17(15 \%)$ & $7(12 \%)$ & 0.6 \\
\hline & Colon & $42(25 \%)$ & $26(23 \%)$ & $16(28 \%)$ & 0.4 \\
\hline & Ileocolonic & $100(60 \%)$ & $68(61 \%)$ & $32(57 \%)$ & 0.18 \\
\hline \multirow[t]{3}{*}{ Disease phenotype } & Penetrating & $74(44 \%)$ & $54(48 \%)$ & $20(36 \%)$ & 0.12 \\
\hline & Stricturing & $45(27 \%)$ & $26(23 \%)$ & $19(34 \%)$ & 0.14 \\
\hline & Perianal & $77(46 \%)$ & $55(49 \%)$ & $22(40 \%)$ & 0.2 \\
\hline \multirow[t]{2}{*}{ Concurrent immunomodulators } & Thiopurines & $114(68 \%)$ & $76(68 \%)$ & $38(68 \%)$ & 0.99 \\
\hline & Methotrexate & $7(4 \%)$ & $3(3 \%)$ & $4(7 \%)$ & 0.18 \\
\hline \multirow{2}{*}{$\begin{array}{l}\text { Postinfusion time to LOR (time of } \\
\text { re-emerging symptoms)* response }\end{array}$} & Early ( $\leq 4$ weeks) & $56(42 \%)$ & $36(41 \%)$ & $20(43 \%)$ & 0.9 \\
\hline & Late (>4 weeks) & $78(58 \%)$ & $51(59 \%)$ & $27(57 \%)$ & 0.9 \\
\hline \multicolumn{2}{|l|}{$\begin{array}{l}\text { Mean number of IFX infusions until } \\
\text { LOR (median) }\end{array}$} & $9 \pm 9(6)$ & $9 \pm 9(6)$ & $8.5 \pm 7(5)$ & 0.8 \\
\hline \multirow[t]{2}{*}{ CRP level before escalation* } & Normal & $37(30 \%)$ & $22(31 \%)$ & $15(29 \%)$ & 0.8 \\
\hline & Elevated & $85(70 \%)$ & $49(69 \%)$ & $36(71 \%)$ & 0.8 \\
\hline
\end{tabular}

For continuous values both the mean and the median (in parentheses) are noted.

*Items for which not all patients' data were available. IFX, infliximab; LOR, loss of response; CRP, C-reactive protein.

\section{RESULTS}

\section{Patient Characteristics}

Two hundred and fifteen double-dosed or intervalhalved CD patients were identified in the participating centers. Of these, 47 were excluded due to missing data $(n=$ $26)$, incorrect classification $(n=13)$, or unclear/alternating escalation protocols $(n=8)$. Thus, there remained 168 patients who comprised the study population. Out of the 168 patients, 34 patients were previously reported together as a double-dose arm (without distinguishing between 10 $\mathrm{mg} / \mathrm{kg} / 8 \mathrm{w}$ to $5 \mathrm{mg} / \mathrm{kg} / 4 \mathrm{w}$ ) in another study. ${ }^{9}$ These patients were included in the present study, but are reported separately corresponding to the two intensification arms. Double-dosing to $10 \mathrm{mg} / \mathrm{kg} / 8$ weeks was the first intensification strategy in $112(67 \%)$ of the patients, whereas in 56 patients $(33 \%)$ the infusion intervals were shortened to every 4 weeks as their first intervention after LOR. The demographic and disease characteristics of the study cohort, stratified into the two treatment groups are depicted in Table 1.

\section{Early Clinical Response}

Overall, 123 out of 168 (73\%) study patients had short-term clinical response to dose intensification (Fig. 1). Eighty-six out of 112 (77\%) patients in the $10 \mathrm{mg} / \mathrm{kg} / 8 \mathrm{w}$ group experienced early response to intensification compared with $37 / 56$ patients $(66 \%)$ in the $5 \mathrm{mg} / \mathrm{kg} / 4 \mathrm{w}$ group (OR $1.7,95 \%$ CI $0.8-3.4, P=0.14$ ).

C-reactive protein (CRP) measurement at the time of LOR before the intensification dosing was available for 122 patients. Elevated CRP above the upper limit of normal was found in 29/34 (85\%) of patients who failed to respond to the intensified dose compared with 56/88 (64\%) of those who responded (OR $3.295 \%$ CI 1.2-9.4, $P=$ 0.02). A complicated disease phenotype was more commonly associated with favorable short-term response to escalation. Thus, 39/45 patients with stricturing disease had 


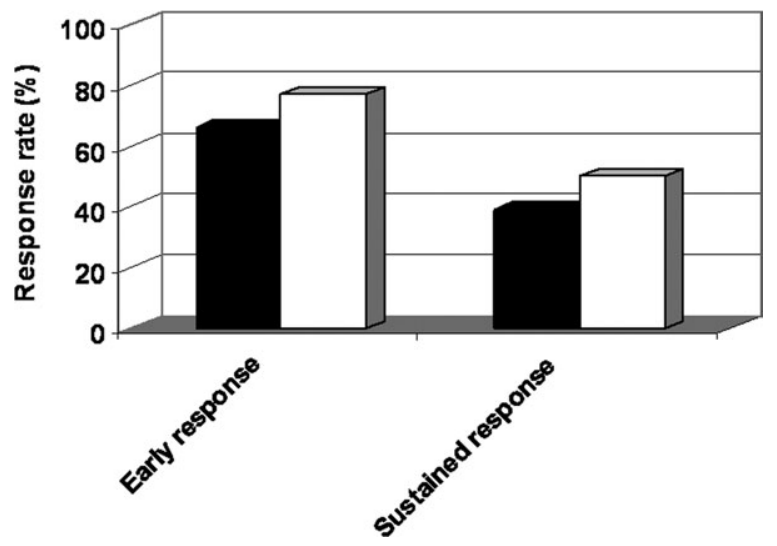

FIGURE 1. Early response rate at 4-8 weeks postescalation and sustained response at 12 months postescalation for dose-doubling (white bars) compared with interval-halving (black bars) strategies.

an early response to escalation compared with 24/49 with an inflammatory phenotype (OR 4.8 , 95\% CI 2.4-18, $P<$ 0.001 ) and $59 / 74$ patients with penetrating disease responded compared with the 24/49 inflammatory phenotype patients (OR 4.1, 95\% CI 1.8-9.1, $P<0.001$ ). On a multivariate analysis, normal CRP, stricturing and penetrating disease have all retained an independent association with short-term response to escalation with statistical significance of $P<0.05$, whereas the type of escalation strategy $(5 \mathrm{mg} / \mathrm{kg} / 4 \mathrm{w}$ or $10 \mathrm{mg} / \mathrm{kg} / 8 \mathrm{w})$ was not correlated with early response $(P=0.4$, data not shown).

\section{Sustained Clinical Response}

Two patients had shorter than 1-year follow-up (one from each group) and were excluded from the analysis of sustained response at 12 months. Out of the remaining 166 patients, $56 / 111(50.4 \%)$ in the $10 \mathrm{mg} / \mathrm{kg} / 8 \mathrm{w}$ group had a sustained clinical response at 12 months after infliximab intensification, compared with $22 / 55$ (39\%) patients in the $5 \mathrm{mg} / \mathrm{kg} / 4 \mathrm{w}$ group (OR 1.5, 95\% CI 0.8-2.9, $P=0.2$, Fig. 1). The Kaplan-Meier curve for sustained response over time during the first 12 months after dose-escalation is shown in Figure 2. Interestingly, eight patients who had early response to escalation were later stepped back down to $5 \mathrm{mg} / \mathrm{kg} / 8 \mathrm{w}$ regimen and have maintained a sustained response. The clinical parameters of patients with or without a sustained 12-month response to escalation are shown in Table 2 along with multivariate analysis of factors found to be associated with sustained response with a statistical significance of $P \leq 0.1$. As can be seen, a nonsmoking status, age of diagnosis between 16-40, and normal CRP at LOR were all independently associated with sustained 12month response to dose intensification.

To verify that the type of escalation $(5 \mathrm{mg} / \mathrm{kg} / 4 \mathrm{w}$ or $10 \mathrm{mg} / \mathrm{kg} / 8 \mathrm{w}$ ) was not associated with the 1 -year outcome, we also repeated this multivariate analysis after including the type of intensification strategy in the model. Similar to the results of the univariate analysis, this analysis failed to detect a statistically significant association of the specific dose-escalation regimen with the sustained response at 1 year (data not shown). The type of LOR, whether no response (symptoms emerging rapidly $<4$ weeks after the last infusion) or shortened response (symptoms arising 5-7 weeks after the infusion) was available for 132 patients. Among the 56 patients who were dose-escalated due to no response, $9 / 20$ who were escalated to $5 \mathrm{mg} / \mathrm{kg} / 4 \mathrm{w}$ responded compared with $19 / 35$ in the $10 \mathrm{mg} / \mathrm{kg} / 8 \mathrm{w}$ group (OR 1, 95\% CI 0.3-3, $P=0.95$ ). Among the 76 patients escalated due to shortened response (symptoms emerging 5-7 weeks after last infusion), $11 / 25$ in the $5 \mathrm{mg} / \mathrm{kg} / 4 \mathrm{w}$ enjoyed a 12 months sustained response compared with 27/ 50 in the $10 \mathrm{mg} / \mathrm{kg} / 8 \mathrm{w}$ group (OR 0.7 , 95\% CI $0.2-1.8$, $P=0.4)$.

\section{Subsequent Therapies After First Dose Escalation}

The course and subsequent therapies employed for the individual study patients are shown in Figure 3. Out of the 87 patients who had primary or secondary LOR to the first dose escalation, 28 (32\%) were further dose-intensified a second time and the rest were switched to other medications or were referred to surgery (Fig. 3). Regained response by the second escalation was experienced by $9 / 28$ (32\%) patients (median follow-up time $4 \pm 15$ months, range 2-48 months). When considered together, the first and second escalations resulted in 87/166 (52\%) of patients being in sustained clinical response at 12 months after initial LOR.

\section{DISCUSSION}

The present study compared the efficacy of halving the infusion intervals of infliximab to once in every 4 weeks with doubling the dose in patients who lost response to standard maintenance regimen. Other alternatives for dose escalation, such as $5 \mathrm{mg} / \mathrm{kg} / 6$ weeks, are probably

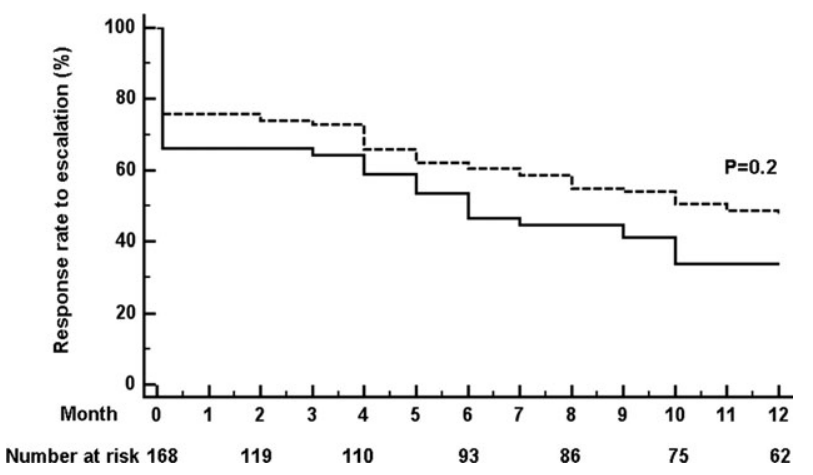

FIGURE 2. Cumulative probability of LOR over time after escalation of infliximab to $5 \mathrm{mg} / \mathrm{kg} / 4 \mathrm{w}$ (solid line) compared with intensification to $10 \mathrm{mg} / \mathrm{kg} / 8 \mathrm{w}$ (dashed line). 
TABLE 2. Uni- and Multivariate Analysis of the Association of Clinical Parameters with Sustained Response Versus the Failure to Achieve Sustained Response to the First Escalation

\begin{tabular}{|c|c|c|c|c|c|c|c|}
\hline & & $\begin{array}{l}\text { Sustained } \\
\text { Response } \\
(n=78)\end{array}$ & $\begin{array}{l}\text { No Sustained } \\
\text { Response } \\
(n=88)\end{array}$ & $\begin{array}{c}\text { Univariate } \\
\text { AnalysisOR } \\
(95 \% \mathrm{CI})\end{array}$ & $P$-value & $\begin{array}{c}\text { Multivariate } \\
\text { Analysis OR } \\
(95 \% \mathrm{CI})\end{array}$ & $P$-value \\
\hline \multicolumn{2}{|l|}{ Female gender } & $39(50 \%)$ & $45(51 \%)$ & $0.95(0.5-1.8)$ & 0.6 & - & - \\
\hline \multicolumn{2}{|l|}{ Mean age (median) } & $35 \pm 12(35)$ & $33 \pm 13(30)$ & $1.3(0.3-2.3)$ & 0.8 & - & - \\
\hline \multicolumn{2}{|l|}{ Smoking* } & 9 & 22 & $0.4(0.2-0.95)$ & 0.03 & $0.4(0.1-1.01)$ & 0.053 \\
\hline \multicolumn{2}{|c|}{ Mean duration of disease, years (median) } & $9.3 \pm 8.5(7)$ & $7.6 \pm 8(4)$ & $1.3(0.7-2.4)$ & 0.09 & $0.9(0.4-2.2)$ & 0.9 \\
\hline \multicolumn{2}{|c|}{ Extra-intestinal manifestations* } & $25(44 \%)$ & $23(36 \%)$ & $1.4(0.7-2.9)$ & 0.4 & - & _- \\
\hline \multicolumn{2}{|l|}{ Prior anti-TNF failure } & $1(1 \%)$ & $3(3 \%)$ & $0.4(0.03-3.7)$ & 0.4 & _- & - \\
\hline \multicolumn{2}{|l|}{ Episodic infliximab therapy* } & $8(12 \%)$ & $14(17 \%)$ & $0.7(0.3-1.7)$ & 0.4 & - & - \\
\hline \multicolumn{2}{|l|}{ Previous intestinal surgery* } & $31(46 \%)$ & $25(35 \%)$ & $1.5(0.8-2.9)$ & 0.2 & _- & - \\
\hline \multirow[t]{3}{*}{ Age at diagnosis* } & $<16$ & $11(14 \%)$ & $16(20 \%)$ & $0.65(0.3-1.5)$ & - & - & \\
\hline & $16-40$ & $61(78 \%)$ & $44(55 \%)$ & $2.9(1.4-5.9)$ & 0.002 & $2.7(1.1-7.7)$ & 0.04 \\
\hline & $>40$ & $6(8 \%)$ & $20(25 \%)$ & $0.25(0.1-0.7)$ & 0.005 & $0.2(0.03-0.9)$ & 0.04 \\
\hline \multirow[t]{4}{*}{ Location } & Upper & $1(1 \%)$ & $6(7 \%)$ & $0.2(0.02-1.5)$ & 0.11 & - & - \\
\hline & Small bowel & $9(12 \%)$ & $15(17 \%)$ & $0.6(0.3-1.5)$ & 0.3 & - & - \\
\hline & Colon & $48(61 \%)$ & $51(58 \%)$ & $1.1(0.6-2.1)$ & 0.6 & _- & - \\
\hline & Ileocolonic & $20(26 \%)$ & $21(24 \%)$ & $1.1(0.5-2.2)$ & 0.8 & _- & - \\
\hline \multirow[t]{3}{*}{ Disease phenotype } & Penetrating & $36(46 \%)$ & $37(42 \%)$ & $1.2(0.6-2.2)$ & 0.6 & - & - \\
\hline & Stricturing & $26(33 \%)$ & $18(20 \%)$ & $1.9(0.96-3.9)$ & 0.06 & $1.4(0.5-3.6)$ & 0.5 \\
\hline & Peri-anal & $39(50 \%)$ & $37(42 \%)$ & $1.4(0.7-2.5)$ & 0.3 & - & - \\
\hline \multirow[t]{2}{*}{ Concurrent immunomodulators } & Thiopurines & $54(81 \%)$ & $58(75 \%)$ & $1.2(0.6-2.3)$ & 0.6 & - & - \\
\hline & Methotrexate & $2(3 \%)$ & $5(6 \%)$ & $0.4(0.1-2.3)$ & 0.3 & _ & - \\
\hline \multirow[t]{2}{*}{ Postinfusion time to LOR } & Early ( $\leq 4$ weeks $)$ & $23(37 \%)$ & $33(47 \%)$ & $0.7(0.3-1.3)$ & 0.2 & _- & - \\
\hline & Late $(>4$ weeks) & $39(63 \%)$ & $37(53 \%)$ & $1.5(0.7-3)$ & 0.2 & - & - \\
\hline \multicolumn{2}{|c|}{$\begin{array}{l}\text { Mean number of IFX maintenance infusions } \\
\text { until LOR (median) }\end{array}$} & $9.4 \pm 8.9(6)$ & $8 \pm 8.8(6)$ & $0.9(0.5-1.7)$ & 0.4 & - & - \\
\hline \multicolumn{2}{|c|}{ Normal CRP before escalation* } & $23(43 \%)$ & $13(19 \%)$ & $3.2(1.4-7.1)$ & 0.005 & $4(1.5-10.3)$ & 0.004 \\
\hline
\end{tabular}

For continuous values both the mean and the median (in parentheses) are noted.

*Items for which not all patients' data were available. IFX, infliximab; LOR, loss of response; CRP, C-reactive protein; OR, odds ratio; CI, confidence interval.

more commonly practiced than the above strategies, ${ }^{9}$ but were not presently examined because their cumulative infliximab doses are not comparable to those of the two dose-doubling strategies. Despite this reservation, an important observation of this study is that even within the choice of two dose-doubling strategies, there is disagreement between IBD physicians on the optimal intensification protocol, resulting in a third of the patients having their infusion intervals halved while the remaining ones were double-dosed. These disparate management approaches likely reflect the fact that there are few data pertaining to the rates of regained response by different dose-escalation strategies, and comparative data between different approaches are particularly lacking. For instance, out of 547 responders to infliximab in one series, $89(16 \%)$ were dose-escalated to $10 \mathrm{mg} / \mathrm{kg} / 8$ weeks and in 108 patients $(19.7 \%)$ the dose intervals were reduced, but no data were provided on how many of these interval reductions were to $5 \mathrm{mg} / \mathrm{kg} / 4$ weeks and no direct comparison between the success of the two approaches was available. ${ }^{10}$ Another group reported on infliximab-treated patients of whom 54\% required dose intensification and $76 \%$ responded. ${ }^{11}$ However, no details were presented regarding the success of the different intensification protocols or the response rate at 12 months postescalation.

Notably, the only infliximab dose-intensification strategy reported in the context of a clinical trial was the escalation to $10 \mathrm{mg} / \mathrm{kg} / 8 \mathrm{w}$ in the ACCENT I study, which was required by $28 \%$ of the patients and yielded a regained response in $88 \%$ of patients. ${ }^{1}$ However, the duration of this regained response was not reported, nor was it compared with other regimens. Thus, ACCENT I could not resolve the best escalation strategy in such circumstances. This question is particularly pertinent given a mathematical 


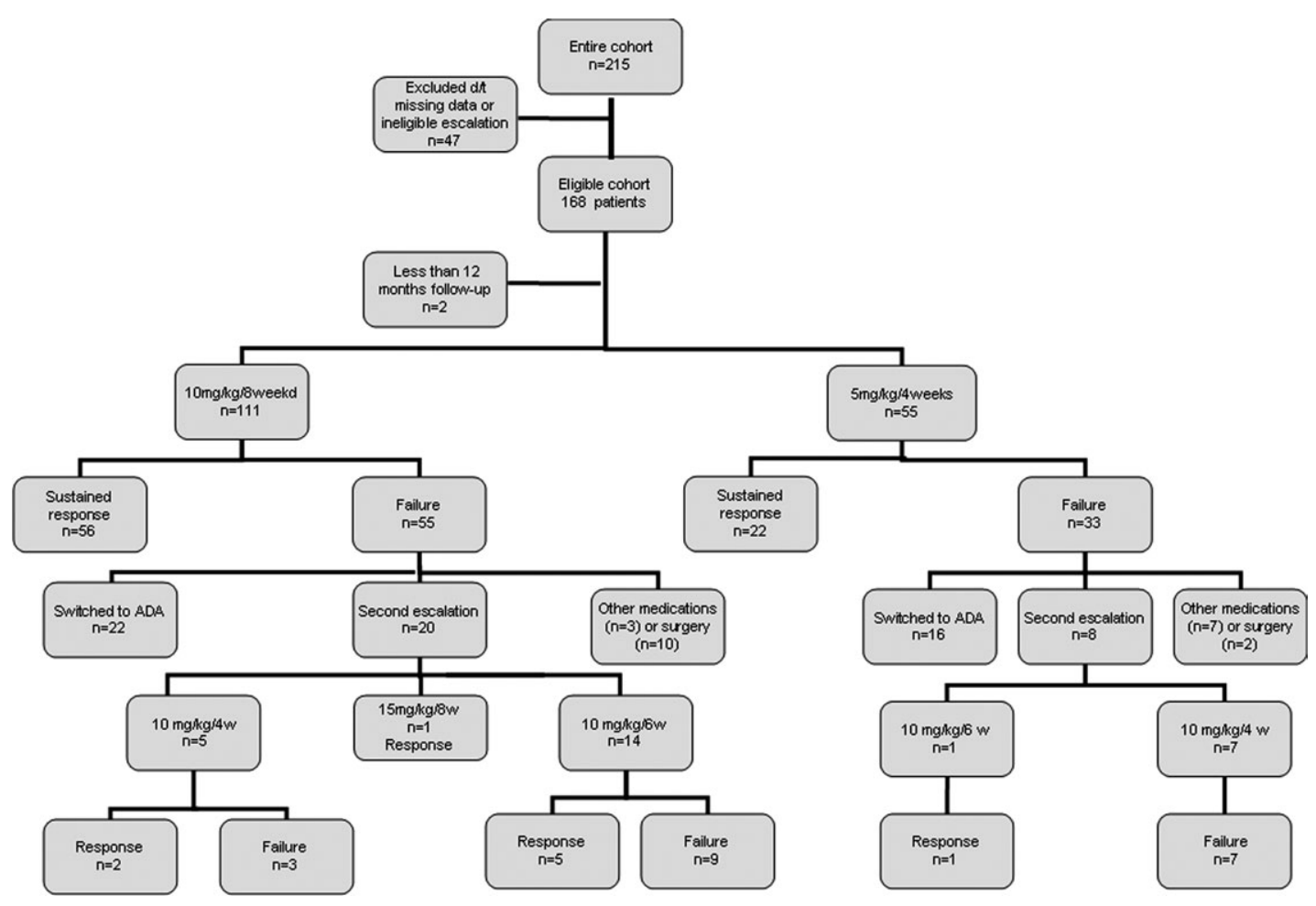

FIGURE 3. The clinical course of the patients treated with escalated dose of infliximab. ADA, adalimumab.

model which suggested that infliximab interval shortening may be superior to an equivalent dose-increase through achieving higher AUC of drug levels in blood. ${ }^{8}$ Moreover, in contrast with infliximab, the registration trials (and clinical practice) of the other anti-TNF agents, adalimumab and certolizumab, have generally advocated halving the intervals between injections rather than doubling the dose in patients losing response to maintenance regimens. ${ }^{12,13}$ Although adalimumab and certolizumab are administered by a subcutaneous route and probably differ from infliximab in their pharmacokinetics, the discrepancy between the basic principles of escalation policy in trials of different anti-TNF agents further underscores the need to explore if one strategy is superior to its counterpart.

The present study is the first to assess the sustained response to escalation by double-dosing versus intervalhalving. To the best of our knowledge, it is also the largest study to date to specifically investigate the outcome of intervention after LOR to infliximab. Based on the published mathematical model of infliximab pharmacokinetics, ${ }^{8}$ we hypothesized at the study conception that halving the interval would prove superior to dose-doubling. However, the results of the present study showed that intensification to $10 \mathrm{mg} / \mathrm{kg} / 8 \mathrm{w}$ was at least as effective as the $5 \mathrm{mg} / \mathrm{kg} / 4 \mathrm{w}$ strategy. Although a numeric trend toward higher efficacy of dose-doubling was demonstrated, this finding should be interpreted cautiously in light of the study limitations. Nonetheless, if corroborated by prospective studies, it may intriguingly imply that higher peak levels of TNF blockade (as provided by $10 \mathrm{mg} / \mathrm{kg} / 8 \mathrm{w}$ ) are more biologically relevant compared with the continuous yet lower level TNF blockade provided by interval-halving. However, additional clinical, pharmacodynamic, and immunologic data are desirable to support this mechanistic hypothesis.

The present study shows that overall $73 \%$ of patients have an early response to the infliximab dose-intensification and nearly half (47\%) sustain their regained response at the clinically meaningful 12 months' timepoint. Prior reports on response to intensification dosing have not reported on sustained clinical response to escalation but rather judged the regained response at differing individual timepoints, even when dose-escalation was permitted as part of a clinical trial. ${ }^{1,10,11}$ This has made it hard to infer sustained clinical response to dose escalation, which is reported in the present study for the first time. It would be desirable that future studies on LOR will also aim to report sustained clinical outcomes at this well-defined timepoint of 12 months postintervention rather than by median follow-up times, thereby facilitating the comparison between studies and between different management strategies.

The findings of our study are also important given the significant costs incurred by these escalation protocols. In fact, based on published U.S. costs of $\$ 662 / 100 \mathrm{mg}$ 
infliximab and $\$ 193$ per day-care infusion service, ${ }^{14}$ keeping a $60-\mathrm{kg}$ patient on $10 \mathrm{mg} / \mathrm{kg} / 8 \mathrm{w}$ for 12 months would cost 24,990 US $\$$ compared with 26,148 US $\$$ for the $5 \mathrm{mg} /$ $\mathrm{kg} / 4 \mathrm{w}$ strategy. This amounts to a $\$ 1,158$ savings in direct cost per patient per annum by the dose-doubling strategy, even before considering the additional indirect costs of lost work days and the greater inconvenience inflicted on the patients by additional clinic visits in the interval-halving strategy. Notably, regimens such as $5 \mathrm{mg} / \mathrm{kg} / 6$ weeks or $7.5 \mathrm{mg} / \mathrm{kg} / 8$ weeks, which were not presently investigated, would reduce the direct costs of treatment further. However, evidence of their comparable efficacy and on the optimal choice of patients for the different escalation strategies is still limited.

Although elevated CRP levels are usually considered to be associated with more favorable outcome of anti-TNF induction therapy, in the present study it was normal CRP that was predictive of response to dose-intensification (Table 2). One possible explanation could be that the contention about elevated CRP correlation with response to antiTNF therapy is not solid enough, especially in light of some large studies which failed to find this association. ${ }^{10}$ However, it is also possible that normal CRP merely marks patients whose emerging symptoms were not due to inflammatory IBD activity and would have resolved regardless of any anti-TNF escalation. This possibility serves to underscore the need to seek evidence for active inflammation in order to establish genuine LOR to anti-TNFs. An alternative explanation may be that this counterintuitive finding of our study indicates that patients with LOR comprise a unique group that is distinguished from the bulk of patients referred for initiation of anti-TNF and are therefore also influenced by a different set of predictive factors of response. Notably, in light of this counterintuitive finding of normal CRP association with sustained response, we also performed a separate analysis restricted to the 85 patients with elevated CRP before escalation. Interestingly, similar results were observed also within this group with validated inflammatory LOR: early response to escalation was achieved in 35/49 compared with 21/36 patients in the dose-doubling versus interval-halving groups, respectively (OR 1.8, 95\% CI 0.7-4.4, $P=0.2$ ), and sustained response was observed in $18 / 49$ compared with $12 / 36$, respectively (OR 1.1, 95\% CI $0.5-2.8, P=0.7$ ). This subanalysis supports the comparability of the two escalation strategies in the subgroup of patients with more definite inflammatory LOR, but future studies are needed to corroborate these and other predictive factors for success of dose intensification.

Several limitations of our study need to be acknowledged. Other less costly and commonly practiced alternatives for dose escalation, such as $5 \mathrm{mg} / \mathrm{kg} / 6 \mathrm{w}$ or $7.5 \mathrm{mg} /$ $\mathrm{kg} / 8 \mathrm{w}$, were not investigated in the present study. This lim- its our study's generalizability only to patients who have received dose-doubling or interval-halving as their first intervention after LOR. It therefore remains possible that many patients would equally benefit from a strategy of 5 $\mathrm{mg} / \mathrm{kg} / 6 \mathrm{w}$, as previously suggested by a small-scale study. ${ }^{9}$ Patients were also not blindly assigned to the two intensification strategies in this retrospective study. Moreover, physicians' decisions may vary over time as other therapies become available. Therefore, a selection bias in physicians' choices of patients for each treatment cannot be definitely excluded, and prospective blinded controlled trials are warranted to stringently define the best escalation strategy. In addition, the present results can by no means be interpreted as suggesting that dose-intensification is superior to switching to another anti-TNF, as this alternative strategy was not examined by our study. Another limitation stemming from the retrospective nature of this study is the lack of standardized clinical scoring scales to define patients' response to escalation, which in turn may introduce significant heterogeneity to the results. However, we believe the patient's report and the clinician's decision regarding continuation or change in the therapeutic regimen probably reflect the real-life experience of disease severity assessment and the ensuing clinical decision-making. Although the participation of multiple centers could increase the heterogeneity of the findings, it also lends further support to the wider clinical relevance of the observations, being derived from several tertiary centers rather than any single center with a particular policy. A cautionary comment should also be made, as this study was not powered to be a noninferiority study. Thus, despite the comparable outcomes of intervalhalving and dose-doubling, we cannot definitively exclude a difference, albeit small, in the efficacy of the two strategies.

Finally, infliximab drug levels and the presence or absence of ATI was previously shown to correlate with LOR, ${ }^{15-17}$ although conflicting results were reported pertaining to the response rate of patients who are IFXATI.$+{ }^{18,19}$ Immunogenicity was not explored in the present study. Thus, it is conceptually possible that dose intensification tailored by infliximab trough levels and antibody measurements could improve the response rate observed in the current study.

In conclusion, dose intensification by interval-halving or dose-doubling collectively induces sustained response for 12 months in $47 \%$ of $\mathrm{CD}$ patients who lost response to standard-dose infliximab. The interval-halving strategy was not found to be superior to the dose-doubling regimen. Given the lower cumulative costs and greater convenience of dose-doubling, this strategy may be preferred over halving the infusion intervals when dose intensification of infliximab is contemplated for patients with LOR. However, these preliminary findings should be corroborated by 
controlled prospective studies to define the optimal intervention (in terms of efficacy, safety, and immunogenicity) for $\mathrm{CD}$ patients with LOR to infliximab.

\section{ACKNOWLEDGMENTS}

Disclosures: Dr. Gisbert has served as a speaker, a consultant, and an advisory member for MSD and Abbott and has received research funding from MSD and Abbott. Dr. Chaparro has received research funding from MSD and Abbott. Dr. Mantzaris has received advisory board fees from Centocor Ortho Biotech, Schering-Plough, Abbott Laboratories, Merck (Hellas), Abbott (Hellas) and UCB (Hellas), and lecture fees from Abbott Laboratories, Ferring Pharmaceuticals, Falk Pharma, Schering-Plough (Hellas), Merck (Hellas), Abbott Laboratories (Hellas), AstraZeneca (Hellas). Dr. Ben-Horin has received consultancy fees from Schering-Plough and Abbot Laboratories. Dr Hart served as a speaker for MSD and Abbott and has received unrestricted education grants from Abbott. Dr. Lakatos has received consultancy fees from Schering-Plough and Abbot Laboratories and lecture fees from Schering-Plough Hungary, and Abbott. Author contributions: SBH conceived and designed the study and drafted the article. L.K. interpreted and analyzed the results, participated in data acquisition and in drafting of the article. J.P.G., B.M., K.L., C.S., G.J.M., A.A., Y.R., A.S., S.S., A.H., P.L.L., P.E., E.I.M., N.S., C.J.W., K.H.K., L.Y., E.V.T., T.N., M.A., I.D., B.L., J.B., J.P.T., P.D.R.H., M.C. participated in data acquisition, interpretation of the results, and critical revision of the article for important intellectual property.

\section{REFERENCES}

1. Hanauer S, Feagan B, Lichtenshtein G, et al. Maintenance infliximab for Crohn's disease: the ACCENT 1 randomized trial. Lancet. 2002; 359:1541-1549.

2. Lichtenstein GR, Yan S, Bala M, et al. Infliximab maintenance treatment reduces hospitalizations, surgeries, and procedures in fistulizing Crohn's disease. Gastroenterology. 2005;128:862-869.

3. Rutgeerts P, Sandborn WJ, Feagan BG, et al. Infliximab for induction and maintenance therapy for ulcerative colitis. $N$ Engl J Med. 2005; 353:2462-2476
4. Rutgeerts P, Feagan BG, Lichtenstein GR, et al. Comparison of scheduled and episodic treatment strategies of infliximab in Crohn's disease. Gastroenterology. 2004;126:402-413.

5. Hanauer SB, Wagner CL, Bala M, et al. Incidence and importance of antibody responses to infliximab after maintenance or episodic treatment in Crohn's disease. Clin Gastroenterol Hepatol. 2004;2:542-553.

6. Ben-Horin S, Chowers Y. Review article: loss of response to antiTNF treatments in Crohn's disease. Aliment Pharmacol Ther. 2011; 33:987-995.

7. Gisbert JP, Panes J. Loss of response and requirement of infliximab dose intensification in Crohn's disease: a review. Am J Gastroenterol. 2009;104:760-767.

8. St. Clair EW, Wagner CL, Fasanmade AA, et al. The relationship of serum infliximab concentrations to clinical improvement in rheumatoid arthritis. Arthritis Rheum. 2002;46:1451-1459.

9. Kopylov U, Mantzaris GJ, Katsanos KH, et al. The efficacy of shortening the dosing interval to once every six weeks in Crohn's patients losing response to maintenance dose of Infliximab. Aliment Pharmacol Ther. 2011;33:349-357.

10. Schnitzler F, Fidder H, Ferrante M, et al. Long-term outcome of treatment with infliximab in 614 patients with Crohn's disease: results from a single-centre cohort. Gut. 2009;58:492-500.

11. Requeiro M, Siemanowski B, Kip K, et al. Infliximab dose intensification in Crohn's disease. Inflamm Bowel Dis. 2007;13:1093-1099.

12. Sandborn WJ, Colombel JF, Schreiber S, et al. Dosage adjustment during long-term adalimumab treatment for Crohn's disease: clinical efficacy and pharmacoeconomics. Inflamm Bowel Dis. 2011;17:141-151.

13. Sandborn WJ, Abreu MT, D'Haens G, et al. Certolizumab pegol in patients with moderate to severe Crohn's disease and secondary failure to infliximab. Clin Gastroenterol Hepatol. 2010;8:688-695.

14. Kaplan GG, Hur C, Korzenik J, Sands BE. Infliximab dose escalation vs. initiation of adalimumab for loss of response in Crohn's disease: a costeffectiveness analysis. Aliment Pharmacol Ther. 2007;26:1509-1520.

15. Ben-Horin S, Yavzori M, Katz L, et al. The immunogenic part of infliximab lies within the Fab fragment, but measurement of antibodies against the intact Infliximab molecule shows superior clinical usefulness. Gut. 2011;60:41-48.

16. Baert F, Noman M, Vermeire S, et al. Influence of immunogenicity on the long-term efficacy of Infliximab in Crohn's disease. $N$ Engl J Med. 2003;348:601-608.

17. Vermeire S, Noman M, Van Assche G, et al. Effectiveness of concomitant immunosuppressive therapy in suppressing the formation of antibodies to infliximab in Crohn's disease. Gut. 2007;56:1226-1231.

18. Afif W, Loftus EV, Faubion WA, et al. Clinical utility of measuring Infliximab and human anti-chimeric antibody concentrations in patients with inflammatory bowel disease. Am J Gastroenterol. 2010; 105:1133-1139.

19. Pariente B, Pineton de Chambrun G, Desroches M, et al. Clinical value of measuring trough levels and human anti-chimeric antibodies in patients with inflammatory bowel disease who lost response to infliximab therapy. J Crohn Colitis. 2011;5:S111-112. 